\title{
Fertility Variation and its Impact on Effective Population Size in Seed Stands of Tamarindus indica and Azadirachta indica
}

\author{
By R. KamalaKannaN ${ }^{1,2)}$, M. VARGHeSE ${ }^{1), 2)}$, J.-M. ParK ${ }^{3)}$, \\ S.-H. KWON ${ }^{3)}$, J.-H. SonG ${ }^{4)}$ and K.-S. KANG ${ }^{\left.3), 5),{ }^{*}\right)}$
}

(Received 19 ${ }^{\text {th }}$ March 2015)

\begin{abstract}
Growth and reproductive traits were assessed in seed stands of two native Indian tree species Tamarindus indica and Azadirachta indica. Positive correlation between growth (height and $\mathrm{GBH}$ ) and reproductive traits (male and female contribution) were found in both species. Fertility was estimated from the flower and fruit production of individuals. Based on the fertility variation among individuals, parental balance, femaleness index and status number $\left(N_{s}\right)$ were determined. The option of equal seed collection among individuals was also considered for estimating $N_{s}$. The percentage of fertile trees was higher in the high flowering year in both species. The best male contributing individuals also showed high female contribution (fruit production). The parental contribution in seed stands showed high deviation from expectation; $20 \%$ individuals contributed about $70 \%$ of male and female gametes in both species. Femaleness index showed that female and male contribution of individual tree was more balanced in the good flowering year, compared to the poor year. Coefficient of variation in male and female fertility was higher in the low flowering year resulting in high fertility variation among individuals and low status number. In T. indica, the female contribution was less variable compared to that of male fertility whereas in A. indica the female fertility variation was higher than that of male fertility. The relative status number

1) Institute of Forest Genetics and Tree Breeding, Coimbatore-641 002, India.

2) Present Address: Life Sciences \& Technology Centre, ITC Ltd. Peenya Industrial Area, Phase I, Bangalore 560 058, India.

$\left.{ }^{3}\right)$ Department of Forest Sciences, Seoul National University, Seoul 08826, Republic of Korea.

$\left.{ }^{4}\right)$ Division of Special-purpose Trees, Korea Forest Research Institute, Suwon 41-350, Republic of Korea.

$\left.{ }^{5}\right)$ Research Institute of Agriculture and Life Sciences, Seoul National University, Seoul 151-921, Republic of Korea.

*) Corresponding author: KYU-SuK KANG.

Tel: +82 28804753 , Fax: +82 28733560 .

E-Mail: kangks84@snu.ac.kr
\end{abstract}

$\left(N_{r}=N_{s} / N\right)$ of the stands was lower for male and female fertility compared to the combined (male and female) fertility of individual trees.

Keywords: status number, effective number of parents, sibling coefficient, gene diversity, equal seed harvest, Tamarindus indica, Azadiracta indica.

\section{Introduction}

Seed is the most commonly used reproductive material for afforestation and plantation forestry. There are three practical ways of improving the genetic quality and productivity of forests, by using seed from appropriate provenances or plus trees, by collecting seed from registered seed stands and by collecting genetically improved seed from seed orchards (ADMAS and KunZe, 1996; FEnNESSY et al., 2007).

A seed stand is defined as a plus stand that is upgraded and opened by removal of undesirable individuals and then cultured for early and abundant seed production (BARNER, 1973; OECD, 1974). Seed stand serves as a useful interim measure to provide seed of improved genetic quality until more intensively selected material is available from seed orchards (Hughes and RobBins, 1982). Seed collected from registered seed stands give some level of genetic improvement including adaptability, vigor and tree form, through elimination of poor genotypes and seed collection from vigorous trees. In contrast, a seed orchard is an intensively-managed plantation of specifically arranged trees for mass production of genetically improved seed for establishment of new forests. It is generally established with grafts, cuttings or tissue culture plantlets propagated from a selected plus tree, or with seedlings produced from selected parents (EL-KASSABY and Askew, 1998). For selecting plus trees, growth traits, pest and disease incidence, tree form and fertility should all be considered (LINDGREN et al., 1997). 
Substantial progress has been made in recent years in improving wood production through tree breeding in India, but adequate quantity of improved seed is not available as breeding programs are in an early stage (FENNESSY et al., 2007). The use of genetically improved planting stock will improve wood yield, encourage large scale production from seed orchards and conserve genetic resources.

Tamarindus indica (Tamarind) and Azadirachta indica (Neem) are tree species indigenous to India that have economic value as food, fuel and medicine. Several agencies are involved in developing improved varieties of these species in India. There is need for large quantities of improved seed but not enough seed stands and seed orchards are available in southern India.

Tamarind is an important multipurpose tropical fruit tree in the Indian subcontinent. Flowering generally occurs in synchrony with new flushing, which in most areas is during spring and summer. Tamarind is a preferentially outcrossing species and it is self-incompatible with negligible amount of selfing (NAGARAJAN et al., 1998). The hermaphroditic bisexual flowers are insect pollinated and usually start bearing fruits at 7-10 years of age, with pod yields stabilizing at approximately 15 years (KULKARNI et al., 1993; BHADORIYA et al., 2011).

Neem is also a native tree species traditionally known for its medicinal value. Neem flowers profusely between February to May and the honey-scented white flowers are a good source of nectar for bees. Pollination occurs by wind and insects, and phenological observations show that trees within a population flower synchronously, but populations vary in the time of onset of flowering (VIKAS, 2011). Natural fruit set is limited by poor pollination and artificial crosspollination could increase the fruit set (VIKAS, 2011).
The objectives of the present study were: 1 ) to study the reproductive traits of two tropical tree species; T. indica and A. indica; 2) to estimate fertility variation among individuals in seed stands; 3) to identify superior trees for immediate seed supply and 4) to get genetic information for management of seed stands in both species.

\section{Materials and Methods}

Fecundity assessment in seed stands

One plantation each of T. indica and A. indica established with bulked seed of superior trees in southern India was selected for evaluating the fertility status of individual trees and diversity of seed crop. Details of climate and location of seed stands are given in Table 1. The stands were thinned from an initial stocking of 400 trees per hectare to retain over 100 trees for seed production. The stands were located in low rainfall sites with a dry season of almost 6 months, April and May being the warmest period of the year.

Growth traits (tree height and girth of stem at breast height, GBH) were recorded at the age of three years in 2006 and fecundity for two consecutive years (2006 and 2007) when $90 \%$ of the trees had flowered, indicating that the trees were mature for seed production and the sites were conducive for good flowering and seed production in the tree species.

The total number of flowers and fruits in individual trees were recorded separately in two occasions when the trees were in peak flowering and also when the fruits were ready for harvest in 2006 and 2007. The total number of flowers was considered as male contribution and the total number of fruits as the female contribution of each tree. The male and female fertility was determined based on estimates of number

Table 1. - Details of location of seed stands.

\begin{tabular}{cccccc}
\hline Species & Location & Latitude & $\begin{array}{c}\text { Longitude } \\
\left({ }^{\circ} \mathrm{N}\right)\end{array}$ & $\begin{array}{c}\text { Rainfall } \\
(\mathrm{mm} / \mathrm{yr})\end{array}$ & $\begin{array}{c}\text { Temperature } \\
\left(\min \sim \max ,{ }^{\circ} \mathrm{C}\right)\end{array}$ \\
\hline Tamarindus indica & Coimbatore & $11^{\circ} 00$ & $77^{\circ} 00^{\prime}$ & 630 & $15 \sim 39$ \\
Azadirachta indica & Namakkal & $11^{\circ} 13^{\prime}$ & $78^{\circ} 10^{\prime}$ & 764 & $14 \sim 40$ \\
\hline
\end{tabular}


of flowers and fruits per tree obtained by extrapolating the flower and fruit counts made on tertiary branches per secondary branch in the total number of primary branches per tree (BILA, 2000). A binocular was used for recording the number of flowers and fruits in representative inflorescences per tertiary branch.

Pearson's correlation coefficient between growth and flowering traits was calculated. Rank correlation was also checked for the male and female fecundity among individuals and between years.

\section{Parental balance and femaleness index}

Parental balance was assessed using a cumulative gamete contribution curve (GRIFFIN, 1982). The number of flowers and fruits produced per individual was sorted in descending order from high to low and the cumulative contribution percentage plotted against the proportion of individuals. In our study, femaleness index $\left(F_{i}\right)$ is defined as the proportion of an individual's reproductive success that is transmitted through its fruit (i.e., as female parents). The femaleness index represents the sexual asymmetry among individuals in their contribution to the next generation (LLOYD, 1979).

$$
F_{i}=\frac{f_{i}}{\left(f_{i}+m_{i}\right)}
$$

where $f_{i}$ and $m_{i}$ are the proportion of fruit and male flower production, respectively, of the $i$-th individual.

\section{Assessment of fertility variation}

The number of male and female gametes produced by an individual is considered to indicate male and female fertility respectively. Fertility variation can be described by sibling coefficient (KANG and LINDGREN, 1999) that is the probability of two genes taken from the gamete gene pool to originate from the same parent.

The sibling coefficient $(\Psi)$ is related to the coefficient of variation $(C V)$ in parental fertility (KANG and LINDGREN, 1998; NIKKANEN and Ruotsalainen, 2000). The sibling coefficient for the parental fertility variation $(\Psi)$ can be derived and divided into male sibling coefficient $\left(\psi_{m}\right)$ and female sibling coefficient $\left(\psi_{f}\right)$ as,

$$
\Psi=N \sum_{i=1}^{N} p_{i}^{2}=0.25\left(C V_{m}^{2}+C V_{f}^{2}\right)+0.5
$$

$$
\begin{aligned}
& \psi_{m}=N \sum_{i=1}^{N} m_{i}^{2}=C V_{m}^{2}+1 \\
& \psi_{f}=N \sum_{i=1}^{N} f_{i}^{2}=C V_{f}^{2}+1
\end{aligned}
$$

where $p_{i}$ is the parental contribution of the $i$-th individual, $C V_{m}$ and $C V_{f}$ are the coefficients of variation in male and female fertility, $N$ is the number of individuals in the population, and $m_{i}$ and $f_{i}$ are the male and female contributions of the $i$-th individual, respectively.

Equal seed harvest is often proposed to control and mitigate the effect of unbalanced contribution among parents in seed stands and orchards (KANG and LINDGREN, 1999; BILA, 2000). Under the equal seed harvest option, the female fertility is kept constant $\left(\psi_{f}=1\right)$. Thus the parental sibling coefficient $\left(\Psi_{e}\right)$ depends only on the male fertility variation and fertility variation under the equal seed harvest can then be expressed as,

$$
\Psi_{e}=\frac{\psi_{m}+3}{4}
$$

\section{Estimate of Status number}

Status number of parent trees $\left(N_{s}\right)$ was calculated as the ratio of census number $(N)$ and the parent sibling coefficient $(\Psi)$. The effective number of male $\left[N_{s(m)}\right]$ and female $\left[N_{s(f)}\right]$ parents was calculated (KIMURA and CROW, 1963; KANG and LINDGREN,1999) from the sibling coefficient of male $\left(\psi_{m}\right)$ and female $\left(\psi_{f}\right)$ fertility variation as,

$$
\begin{aligned}
& N_{s}=\frac{N}{\Psi} \\
& N_{s(m)}=\frac{N}{\psi_{m}} \\
& N_{s(f)}=\frac{N}{\psi_{f}}
\end{aligned}
$$

The effective number of parents $\left[N_{s(e)}\right]$ under the option of equal seed harvest among all individuals was estimated as,

$$
N_{s(e)}=\frac{N}{\Psi_{e}}
$$

where $N$ is the census number of parents in the seed stand. Relative effective number $\left(N_{r}\right)$ is the inverse of the sibling coefficient (i.e., $N_{r}=1 / \psi$ ) or the ratio of effective number to the census number of trees in the seed stand (i.e., $N_{r}=N_{s} / N$ ). 


\section{Results}

\section{Growth and fecundity}

Height and GBH (girth of stem at breast height) varied substantially among individual trees in both species ranging from $1.5-7.5 \mathrm{~m}$ and $6.3-64.0 \mathrm{~cm}$ in $T$. indica, and $3.0-7.0 \mathrm{~m}$ and $6.0-38.5 \mathrm{~cm}$ in $A$. indica, respectively. This variation could be due to difference in origin and adaptability of mother trees from which seeds were collected for establishing the stand, variability of sites or genotypic variation of trees. But most of the trees were fertile indicating the age of maturity of trees for seed collection (Table 2). The percentage of fertile trees was higher in 2007 than in 2006 which resulted in greater male and female contribution of individual trees. The individuals that produced more flowers also contributed more fruits in the stands consistently in both years.

There was a significant correlation between growth traits (height and GBH) and male and female contribution in both species (Table 3). The correlation between growth and reproductive traits was however slightly different in T. indica compared to A. indica (Table 3) since the correlation in $T$. indica across two years was not as consistent as in A. indica.

Though male and female contribution of individual trees was generally correlated in both species there was no significant correlation between growth (height and GBH) and fertility in $T$. indica in the low flowering year, 2006. But GBH was significantly correlated with male fertility and fruit production in 2007 (Table 3). In

Table 2. - Growth (height and GBH) and fecundity in seed stands of Tamarind and Neem in two years (2006 and 2007).

\begin{tabular}{|c|c|c|c|c|c|c|c|}
\hline \multirow{2}{*}{ Species } & \multirow{2}{*}{$N$} & \multicolumn{2}{|c|}{ Growth traits } & \multicolumn{2}{|c|}{ No. of flowers (Male) } & \multicolumn{2}{|c|}{ No. of lruits (t emale) } \\
\hline & & Height(m) & GBHI $(\mathrm{cm})$ & 2006 & 2007 & 2006 & 2007 \\
\hline Tamarindus indica & 108 & 5.1 & 36.4 & $\begin{array}{c}34,379 \\
(63.9)\end{array}$ & $\begin{array}{c}53,051 \\
(90.7)\end{array}$ & $\begin{array}{c}948 \\
(61.1)\end{array}$ & $\begin{array}{l}1,173 \\
(84.3)\end{array}$ \\
\hline Azadiracha indica & 117 & 5.2 & 22.3 & $\begin{array}{l}67,163 \\
(94.9)\end{array}$ & $\begin{array}{c}155,086 \\
(98.3)\end{array}$ & $\begin{array}{c}396 \\
(93.2)\end{array}$ & $\begin{array}{c}6,688 \\
(94.0)\end{array}$ \\
\hline
\end{tabular}

* Growth (height and GBH) recorded in 2006. Percentage of fertile trees given in parenthesis.

Table 3. - Pearson's correlation coefficient between growth traits, and male and female contribution in seed stands of Tamarind and Neem (assessed in 2006 and 2007 - designated as 06 and 07).

T. indica Height GBH 06Male 06Fem 07Male

A. indica Height GBH 06Male 06Fem 07Male

\begin{tabular}{|c|c|c|c|c|c|c|c|c|c|c|c|}
\hline GBH & $0.67^{* *}$ & - & & & & $\mathrm{GBH}$ & $0.88^{* *}$ & - & & & \\
\hline 06Male & 0.16 & 0.22 & - & & & 06 Male & $0.39^{* *}$ & $0.49 * *$ & - & & \\
\hline 06 Fem & 0.19 & 0.23 & $0.95 * *$ & - & & $06 \mathrm{Fem}$ & $0.26^{\text {* }}$ & $0.36^{\text {** }}$ & $0.57^{* *}$ & - & \\
\hline 07Male & 0.17 & $0.37^{* *}$ & $0.58 * *$ & $0.54 * *$ & - & 07Male & $0.41^{* *}$ & $0.55^{* *}$ & $0.65^{* *}$ & $0.34 * *$ & - \\
\hline 07Fem & 0.16 & $0.35^{* * *}$ & $0.52 * *$ & $0.52^{* *}$ & $0.89 * *$ & 07Fem & $0.30^{* *}$ & $0.44^{* * *}$ & $0.47^{* *}$ & $0.46^{* *}$ & $0.45^{* * *}$ \\
\hline
\end{tabular}

** Significant at $0.01, *$ Significant at 0.05 probability level. 

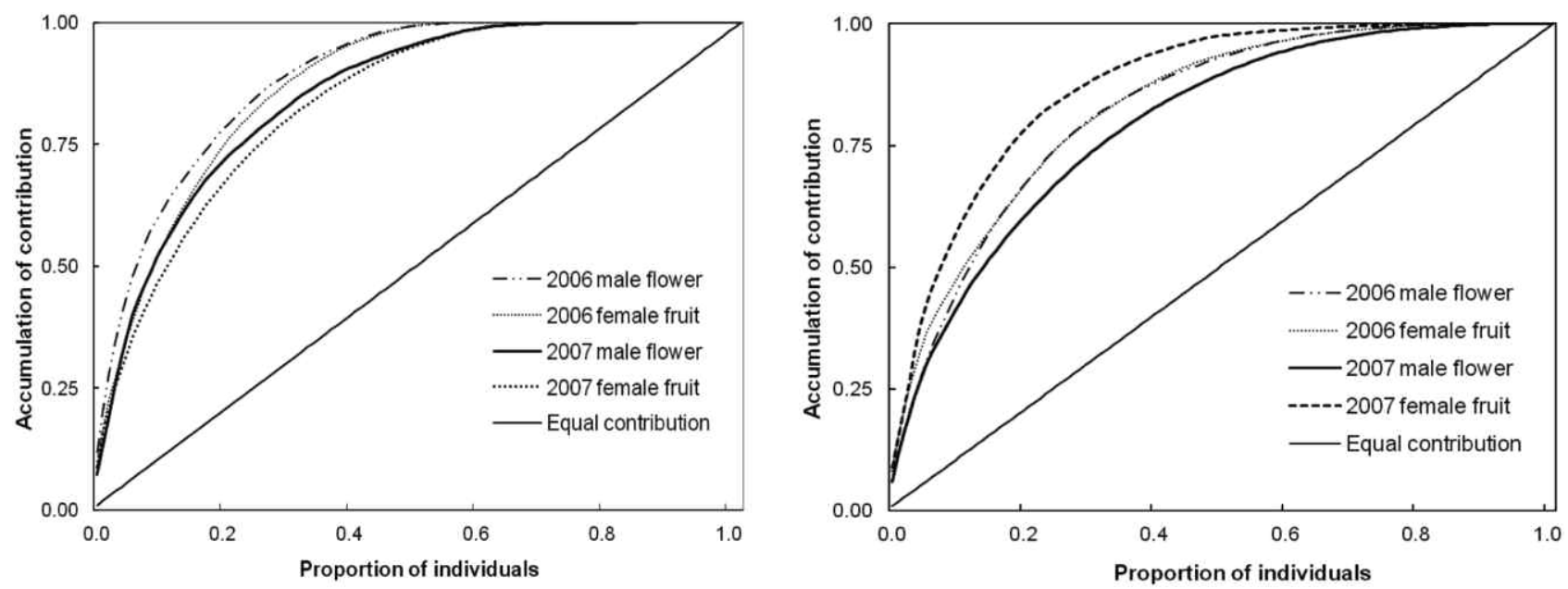

Figure 1. - Cumulative contribution curve in seed stands of Tamarind (left) and Neem (right) based on male and female fertility. Straight line represents equal contribution among individuals.
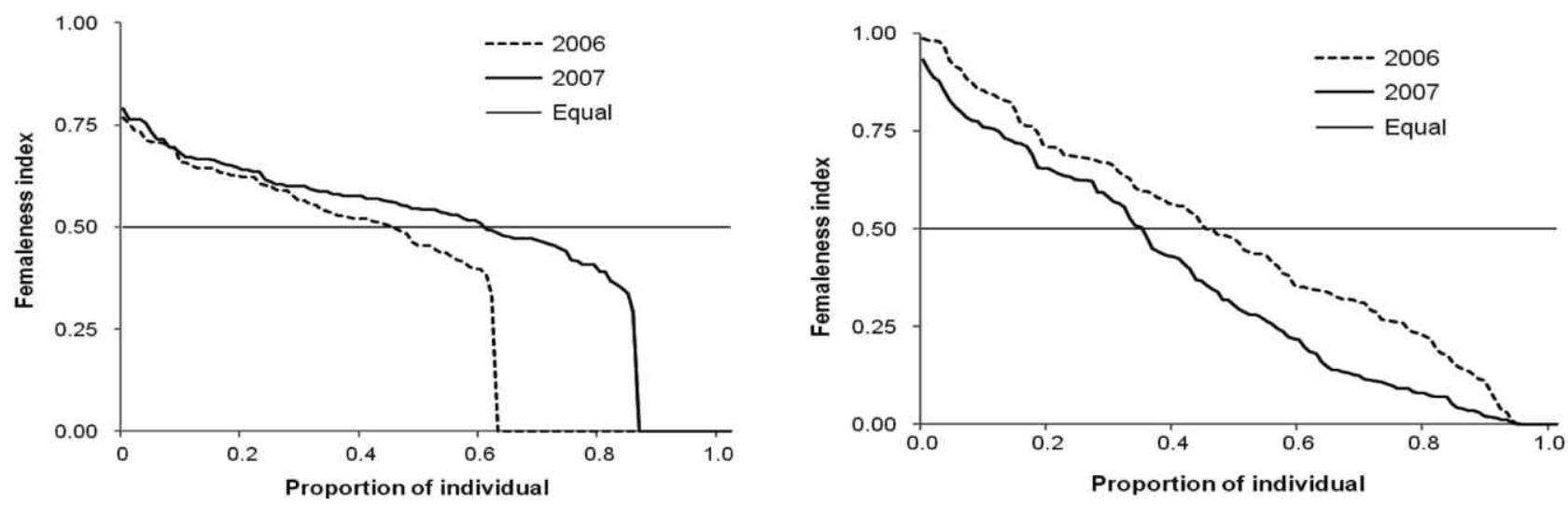

Figure 2. - Femaleness index in seed stands of Tamarind (left) and Neem (right). Horizontal straight line represents equal contribution between genders.

A. indica, height and GBH were significantly correlated with male and female fertility in both years (Table 3).

\section{Cumulative contribution and femaleness index}

There was great deviation from expected parental balance of equal contribution in male and female fecundity in both years (Fig. 1). The representation was skewed with $70 \%$ male and female contribution in the seed crop from $20 \%$ trees in both species. In A. indica, the cumulative curve of female contribution deviated more from that of male fertility (Fig. 1). There was no contribution from $10 \%$ trees in the $A$. indica stand. Climate difference across years can alter the genetic makeup of the seed crop as seen in the drastic difference between male and female fertility in Neem in 2007 (Table 2).

In $T$. indica, the femaleness index showed that about $38 \%$ trees did not contribute to fruit production in 2006 (Fig. 2). The situation improved in 2007 with $87 \%$ trees contributing fruits. The femaleness index varied from 0.25-0.75 which indicated moderate gender balance between male and female fertility in Tamarind (Fig. 2).

In $A$. indica, the distortion of gender balance was evident in both years (Fig. 2). About 20\% trees contributed more strongly as female parents and about $60 \%$ of trees acted more as male parents, compared to the scenario of equal contribution.

\section{Fertility variation and effective number}

The coefficient of variation of male and female fertility was lower in two species in 2007 (except female contribution of $A$. indica) compared to that of 2006. Reduction in $C V$ had influenced fertility variation (sibling coefficient) and effective number (Table 4). In T. indica, the 
Table 4. - Coefficient of variation $\left(C V_{m}\right.$ and $\left.C V_{f}\right)$, sibling coefficient ( $\psi_{m}$ and $\left.\psi_{f}\right)$, effective number $\left[N_{e(m)}\right.$ and $\left.N_{e(f)}\right]$ and relative effective number $\left[N_{r(m)} \& N_{r(f)}\right]$ for male and female gene pool over two consecutive years in seed stands.

\begin{tabular}{|c|c|c|c|c|c|c|c|c|c|c|c|c|}
\hline & \multicolumn{6}{|c|}{ Tomarindas indica $(N-108)$} & \multicolumn{6}{|c|}{ Azadirachio indica $(\mathrm{M}-117)$} \\
\hline & \multicolumn{2}{|c|}{ Male llower } & \multicolumn{2}{|c|}{ Femala fruit } & \multicolumn{2}{|c|}{ Combined } & \multicolumn{2}{|c|}{ Male flower } & \multicolumn{2}{|c|}{ Female fruit } & \multicolumn{2}{|c|}{ Combined } \\
\hline & 2006 & 2007 & 20066 & 2007 & 2006 & 2007 & 2006 & 2007 & 2006 & 2007 & 2006 & 2007 \\
\hline$C V_{m}$ and $C V_{f}^{*}$ & 2.00 & 1.60 & 1.69 & 1.53 & - & - & 1.37 & 1.26 & 1.54 & 1.80 & - & - \\
\hline$\psi_{m,}, \psi_{r}$ and $\Psi$ & 4.99 & 3.57 & 3.87 & 3.33 & 2.22 & 1.73 & 2.88 & 2.60 & 3.38 & 4.24 & 1.57 & 1.71 \\
\hline$N_{s i\left(m_{i}, p\right.}, N_{s(l)}$ and $N_{s}$ & 21.6 & 30.2 & 27.9 & 32.4 & 48.7 & 62.5 & 40.7 & 45.1 & 34.6 & 27.6 & 74.8 & 68.5 \\
\hline$N_{r(t, i, j}, N_{r(n)}$ ands $N_{r}$ & 0.20 & 0.28 & 0.26 & 0.30 & 0.45 & 0.58 & 0.35 & 0.39 & 0.30 & 0.24 & 0.64 & 0.59 \\
\hline
\end{tabular}

* $m$ and $f$ represent male and female parents, respectively.

Table 5. - Sibling coefficient $\left(\Psi_{e}\right)$, effective number $\left[N_{s(e)}\right]$ and relative effective number $\left[N_{r(e)}\right]$ for two successive years estimated for equal seed harvest among individuals, which assumed that female fertility variation was constant and equal to one.

\begin{tabular}{|c|c|c|c|c|}
\hline & \multicolumn{2}{|c|}{ Tanarindus indica } & \multicolumn{2}{|c|}{ Azadirachta indica } \\
\hline & 2006 & 2007 & 2006 & 2007 \\
\hline$\Psi_{0}$ & 2.00 & 1.64 & 1.47 & 1.40 \\
\hline$N_{s(w)}$ & 54.0 & 65.7 & 79.6 & 83.6 \\
\hline$N_{f\left(x^{2}\right)}$ & 0.50 & 0.61 & 0.68 & 0.71 \\
\hline
\end{tabular}

$C V$ of female fertility was less than that of male fertility implying that contribution of female parent was less skewed than that of male parent. In A. indica, however, the female fertility variation among individuals was larger than male fertility variation (Table 4). The female fertility variation (sibling coefficient) was higher in 2007 with lower effective number of female parents compared to 2006, even though the fruit production was higher in 2007. In both species the relative effective number of male and female parents was low ranging from 0.20 to 0.39 during the two consecutive years (Table 4 ). When male and female fertility variations were combined, the relative effective number of parents increased (Table 4).

If the relative effective number is low, management practices like rouging of poor flowering trees and collecting equal amount of seed from individuals in the seed stand should be considered for balancing the contribution of parent trees. Equal seed harvest will increase the effective number of contributing trees by reducing the fertility variation among individuals (Tables 4 and 5). The combined relative effective number $\left(N_{r(e)}\right)$ was higher in 2007 in tamarind, whereas it was low in Neem due to variability in fruit production among the trees (Table 5).

\section{Discussion}

High flowering is generally associated with low fertility variation among individuals in an orchard ensuring good contribution to the next generation (EL-KASSABY and REYNOLDS, 1990; KANG and EL-KassabY, 2002). Even in good flowering years climatic factors and site conditions may cause distortion in gender contribu- 
tion of parent trees. This phenomenon is evident (Tables 2 and 4) from the variability in fruit production of $A$. indica in 2007. Distortion in gender contribution (i.e., femaleness index; Fig. 2) may cause large variability in the seed crop since most individuals deviated from the horizontal line (balance between genders). High femaleness index indicates that the individual is contributing more as a female than as a male parent compared to other individuals in the population (BURCZYK and CHALUPKA, 1997). Several weather parameters may be associated with onset of flowering and receptivity as well as pollen release which influence the composition of the seed crop.

Significant correlation between GBH and reproductive traits (Table 3) can be used to manage the stand for reducing self-pollination in parent trees and thereby enhance fruit production. Compared to tree height, the GBH can be easily measured and used as an indirect key for selection of good flowering trees (KANG and EL-KASSABY, 2002).

Sibling coefficients $(\Psi)$ were considerably higher than 1.0 (Table 4) when male and female fertilities were considered independently, indicating that individual trees contributed differently to the gamete gene pool. However sibling coefficients were low when gender fertility was combined indicating good exchange of genes in the population. The $\Psi$ expresses how much parents vary in their contribution to the gene pool because it raises the probability that sibs would occur when compared to the situation of no difference in fertility among individuals (KANG et al., 1999). All individuals contribute to the overall fertility in a population, which is the ability to produce genes transmitted to the offspring. If $\Psi$ equals 1.0, all individuals have the same fertility.

When the relative effective number is estimated to be low in any production population (e.g., seed stands and seed orchards) certain management options may be adopted to reduce fertility variation and enhance genetic diversity (ADMAS and KUNZE, 1996; KAMALAKANNAN and VARGHESE, 2008). Thinning low flowering individuals and harvesting seeds equally from each tree can be applied effectively in the stands since there is significant correlation between $\mathrm{GBH}$ and fertility in both species.

A seed stand is expected to produce good quality seed and should be managed to maximize seed production (ELEVITCH, 2004). It is a good practice to mark the trees before seed collection to estimate the effective population size of seed crop and evaluate the contribution of each tree in different years. Tamarind trees are seen to be more stable in their fertility and gender contribution compared to Neem as evidenced by the pattern across two successive years. Fruit set in Tamarind is around $2 \%$ in both years whereas in Neem fruit set varied considerably between the low flowering $(0.59 \%)$ and high flowering (4.3\%) years. In A. indica, there was drastic difference in fruit set in two consecutive years but not much difference in percentage of flowering trees. Low flowering did not have a big impact on predicted diversity of seed crop in A. indica as evidenced by the low sibling coefficient value and the high relative population size.

Fertility was affected by climatic differences in both species in two successive years, with a significantly higher flowering in 2007. Neem responded to the climate difference by substantial reduction in fruit set in 2006 without much reduction in percentage of flowering trees. Tamarind responded to the climate difference with a drop in percentage of flowering trees while maintaining the flower to fruit ratio. There was no contribution from $10-35 \%$ trees in two years but there was fair equality in gender contribution in Tamarind.

In Neem, there is a gradation in the femaleness of trees. This adaptation enables the tree species to maintain diversity in seed crop across different years. Hence it is vital to monitor the trees for flowering and fruit set each year before seed collection. It would also be very useful to number the trees serially in the seed stand and maintain record of the mother trees harvested each year. Mixing seed of different years would thus be a very effective strategy to enhance the effective population size in the seed crop.

Genetic relatedness among individual trees and pollen contamination from outside were ignored in this study. There might be some coancestry among individuals if they have originated from the same mother or father (half sibs or full sibs). If all individuals $(N=108)$ of Tamarindus indica are assumed to be half-sibs, loss of genetic diversity would be $1 /\left(2 \times N_{s}\right)=$ $1 /(2 \times 48.7)=0.0103$ in the seed crop in 2006 (Table 4), which is $1.03 \%$, compared to the parental population (KANG and LINDGREN, 1999; BILA, 2000). If coancestry exists, the effective number could be lower than observed, whereas pollen contamination from outside trees would 
enhance the effective population size of seed crop. Pollen contamination from inferior trees would lead to loss in genetic gain but enhance gene diversity (EL-KASSABY et al., 1989; TORIMARU et al., 2013). Gene diversity is essential for high fruit production as both the tree species have self-incompatibility mechanisms to prevent inbreeding. Genetic quality of seed can be maintained if seeds are harvested in good flowering years and mixing seed from different years would help in maintaining diversity in the seed crop.

\section{Acknowledgement}

We are grateful to ARUTSELVAN, MUTHIRIAN and CHEZHIAN for their valuable field support. This work was supported by SIDA and Korea Institute of Planning and Evaluation for Technology in Food, Agriculture, Forestry and Fisheries (IPET) through Agri-Bioindustry Technology Development Program, funded by Ministry of Agriculture, Food and Rural Affairs (MAFRA) (No. 314009-3)

\section{References}

Admas, G. W. and H. A. Kunze (1996): Clonal variation in cone and seed production in black spruce seed orchards and management implications. For. Chron. 72: 475-480.

BARNER, H. (1973): Classification of sources for procurement of forest reproductive material. Report FAO/DANIDA Training Course on Forest Tree Improvement. Kenya: 110-138.

Bhadoriya, S. S., A. GANeshPuRKar, J. NARWARIA, G. RAI and A. P. JAIN (2011): Tamarindus indica: Extent of explored potential. Pharmacogn Rev. 5: 73-81.

BiLA, A. D. (2000): Fertility variation and its effect on gene diversity in forest tree populations. Ph.D. thesis. Swedish University of Agricultural Sciences, Umeå, Sweden. 31p.

BurCzYK, J. and W. ChAlupKA (1997): Flowering and cone production variability and its effects on parental balance in a Scots pine clonal seed orchard. Ann. Sci. For. 54: 129-144.

Elevitch, C. R. (2004): The Over story Book - Cultivating Connections with Trees, $2^{\text {nd }}$ Edition. Permanent Agricultural Resources, Holualoa, Hawaii, USA. URL:http://www.agroforestry.net

El-Kassaby, Y. A. and G. R. Askew (1998): The relationship between reproductive phenology and reproductive output in determining the gametic pool profile in a Douglas-fir seed orchard. For. Sci. 37: 827-835.

EL-KASSABY, Y. A. and S. REYNOLDS (1990): Reproductive phenology, parental balance and supplemental mass pollination in a Sitka spruce seed orchard. For. Ecol. Manage. 31: 45-54.

El-Kassaby, Y. A., D. Rudin and R. YAZDANI (1989): Levels of outcrossing and contamination in two Pinus sylvestris L. seed orchards in northern Sweden. Scand. J. For. Res. 4: 41-49.

Fennessy, J., J. Hubert, S. SAmuel and P. Savill (2007): The importance of seed stands in broadleaved forestry. CONFOD reproductive material No. $13.4 \mathrm{p}$.

GRIFFIN, A. R. (1982): Clonal variation in radiate pine seed orchards I. Some flowering, cone and seed production traits. Aust. For. Res. 12: 295-302.

Hughes, C. E. and A. M. J. Robbins (1982): Seed stand establishment procedures for Pinus oocarpa and Pinus caribaea var. hondurensis in the natural forests of Central America. Commonw. For. Rev. 61(2): 107-113.

KAMALAKANNAN, R. and M. VARGhese (2008): Mixing of seed crops from different years is an effective management strategy for enhancing effective population sizes in Eucalyptus seedling seed orchard crops. In: LINDGREN D. (Editor), Proceedings of a Seed Orchard conference. Umea, 26-28 September, 2007. pp 104-113.

KANG, K. S. and D. LINDGREN (1998): Fertility variation and its effect on the relatedness of seeds in Pinus densiflora, $P$. thunbergii and P. koraiensis clonal seed orchards. Silvae Genet. 47: 196-201.

KANG, K. S. and D. LINDGREN (1999): Fertility variation among clones of Korean pine and its implications on seed orchard management. For. Genet. 6: 191-200.

KANG, K. S. and Y. A. El-Kassaby (2002): Considerations of correlated fertility between genders on genetic diversity: Pinus densiflora seed orchard as a model. Theor. Appl. Genet. 105(8): 1183-1189.

KimurA, M. and J. F. CRow (1963): The measurement of effective population number. Evolution, 17: 279-288.

Kulkarni, R. S., S. Gangaprasad and G. S. SwAmy (1993): Tamarindus indica: Economically an important minor forest product. Minor Forest Prod News 3: $6 \mathrm{p}$.

LindGREN, D., R.-P. WeI and S. LEE (1997): How to calculate optimum family number when starting a breeding program. For. Sci. 43(2): 206-212.

LLOYD, D. G. (1979): Parental strategies of angiosperms. N.Z. J. Bot. 17: 595-606.

Nagarajan, B., A. Nicodemus, A. K. Mandal, R. K. Verma, K. GireEsan and N. P. VAN Mahadevan (1998): Phenology and controlled pollination studies in Tamarind. Silvae Gentica 47: 237-241.

NikKanen, T. and S. Ruotsalainen (2000): Variation in flowering abundance and its impact on the genetic diversity of the seed crop in a Norway spruce seed orchard. Silva Fen. 34: 205-222.

OECD (1974): OECD Scheme for the Control of Forest Reproductive Material Moving in International Trade. OECD Directorate for Agric. and Food, Paris. 24 p. 
Torimaru, T., U. Wennström, B. Andersson, C. AlMQVIST and X.-R. WANG (2013): Reduction of pollen contamination in Scots pine seed orchard crop by tent isolation. Scand J For Res 28(8): 715-723.
VIKAS, R. T. (2011): Reproductive biology of Azadirachta indica (Meliaceae), a medicinal tree species from arid zones. Plant Species Biology 26(1): 116-123.

\title{
Morphological characterization and in vitro germination of heat-treated pollen in Eucommia ulmoides
}

\author{
By S. Song ${ }^{1), 2), 3), 5)}$, J. Tian ${ }^{4), 5)}$, Y. Li ${ }^{1), 2), 3), 5)}$, F. Shang ${ }^{1), 2), 3)}$, X. KAnG ${ }^{1), 2), 3)}$ and J. WANG ${ }^{1), 2), 3), *)}$
}

(Received 27th March 2015)

\begin{abstract}
Polyploid breeding has the potential to increase the economic secondary metabolites of Eucommia ulmoides. However, pollination with induced ploidy-mixed pollen has failed to produce polyploids (GAO, 2006). In this investigation, the morphological characterization and in vitro germination of heat-induced ploidy-mixed pollen of $E$. ulmoides were analysed to determine why there is no polyploid production. Heat-treated pollen grains were easily distinguished as large and small according to their length. The large pollen grains were significantly longer than both untreated and heattreated small samples, suggesting that they were probably $2 \mathrm{n}$ pollen. Rather than the three germinal pores in small pollen, the large grains typically had four pores and, in some cases,

1) National Engineering Laboratory for Tree Breeding, Beijing Forestry University, Beijing 100083, People's Republic of China.

$\left.{ }^{2}\right)$ Key Laboratory of Genetics and Breeding in Forest Trees and Ornamental Plants, MOE, Beijing Forestry University, Beijing 100083, People's Republic of China.

$\left.{ }^{3}\right)$ College of Biological Sciences and Technology, Beijing Forestry University, Beijing 100083, People's Republic of China.

$\left.{ }^{4}\right)$ The Academy of Forestry, Beijing Forestry University, Beijing 100083, People's Republic of China.

5) SHAOYU SONG, JU TIAN and YUN Li contributed equally to this work.

*) Address correspondence to: P. O. Box 118, Beijing Forestry University, NO.35, Tsinghua East Rd., Haidian District, Beijing 100083, People's Republic of China. Tel.: +86-10-62338105.

E-Mail: wangjun@bjfu.edu.cn
\end{abstract}

shallow furrows, which might affect their germination. Although the maximal germination rates of the treated small and large pollen were not significantly different, the large pollen germinated tardily during the early stages of incubation. The small pollen maintained its growth during the incubation, but the tube growth of large pollen almost stopped after $24 \mathrm{~h}$ incubation. Both vegetative and generative nuclei in the large pollen moved into tubes later than in small pollen and the frequency of mitosis in generative nuclei of large pollen was low. Therefore, the tardy germination, poor tube growth, and weak activity of both vegetative and generative nuclei probably caused the poor competition of large pollen in certation. Finally, techniques to increase the competition of highploidy pollen and the prospect of $2 \mathrm{n}$ female gamete induction in the polyploid breeding program of E. ulmoides are discussed.

Key Words: Eucommia ulmoides Oliver; heat-treated pollen; polyploid breeding; poor competition; tardy germination

\section{Introduction}

Eucommia ulmoides Oliver $(2 \mathrm{n}=2 \mathrm{x}=34)$, an endangered deciduous tree species distributed in central and eastern China, is an important economic resource for the herbal medicine and the organic chemical industry (YAO et al., 2012). Some phytochemicals of $E$. ulmoides leaves have been demonstrated to exhibit a wide range of biological activities, such as antioxidant activity, 